\title{
Socioeconomic position in early life, birth weight, childhood cognitive function, and adult mortality. A longitudinal study of Danish men born in 1953
}

\author{
M Osler, A-M N Andersen, P Due, R Lund, M T Damsgaard, B E Holstein
}

See end of article for authors' affiliations

\section{Correspondence to:}

Dr M Osler, Department of Social Medicine, Institute of Public Health, University of

Copenhagen, Blegdamsvej 3, 2200 Copenhagen $\mathrm{N}$, Denmark;

M.Osler@pubhealth.ku.dk

Accepted for publication 5 March 2003

\begin{abstract}
Objective: To examine the relation between socioeconomic position in early life and mortality in young adulthood, taking birth weight and childhood cognitive function into account.

Design: A longitudinal study with record linkage to the Civil Registration System and Cause of Death Registry. The data were analysed using Cox regression.

Setting: The metropolitan area of Copenhagen, Denmark.

Subjects: 7493 male singletons born in 1953, who completed a questionnaire with various cognitive measures, in school at age 12 years, and for whom birth certificates with data on birth and parental characteristics had been traced manually in 1965. This population was followed up from April 1968 to January 2002 for information on mortality.

Main outcome measures: Mortality from all causes, cardiovascular diseases, and violent deaths. Results: Men whose fathers were working class or of unknown social class at time of birth had higher mortality rates compared with those whose fathers were high/middle class: hazard ratio $1.39195 \% \mathrm{Cl}$ 1.15 to 1.67$)$ and $2.04(95 \% \mathrm{Cl} 1.48$ to 2.83$)$ respectively. Birth weight and childhood cognitive function were both related to father's social class and inversely associated with all cause mortality. The association between father's social class and mortality attenuated $\left(\mathrm{HR}_{\text {working class }} 1.30\right.$ (1.08 to 1.56); $\mathrm{HR}_{\text {unkown class }} 1.81$ (1.30 to 2.52)) after control for birth weight and cognitive function. Mortality from cardiovascular diseases and violent deaths was also significantly higher among men with fathers from the lower social classes.

Conclusion: The inverse association between father's social class at time of birth and early adult mortality remains, however somewhat attenuated, after adjustment for birth weight and cognitive function.
\end{abstract}

R ecently, we have experienced an increased research interest in early life origins of adult chronic disease, and a number of birth cohort studies have shown that social factors operating during early life are related to mortality in adult life. ${ }^{1-5}$ The social environment in early life has also been linked to birth weight and childhood cognitive function, ${ }^{6-8}$ which are both related to mortality later in life. ${ }^{8-10}$ Furthermore, some studies have related size at birth to cognitive function in childhood or adolescence. ${ }^{11-13}$ Thus, as figure 1 suggests low birth weight and impaired cognitive function are possible mediators of the relation between socioeconomic position in early life and adult mortality. So far, however, no study has examined whether this relation is accounted for by, or acts independently of, birth weight and childhood cognitive function.

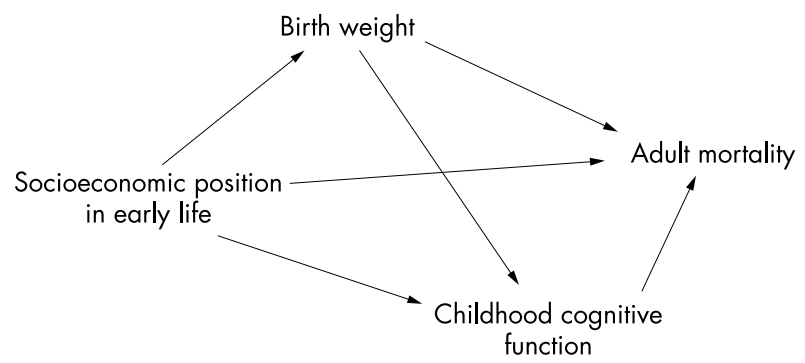

Figure 1 Schematic representation of the examined potential pathways between socioeconomic position in early life and adult mortality, addressed in this study.
In this study, we analyse the relation between socioeconomic position in early life (that is, father's social class and mother's marital status at time of birth) and mortality in young adulthood in a cohort of Danish men born in 1953. The data allow us to look at later all cause and cause specific mortality, taking information on birth weight and childhood cognitive function into account. We also examine whether early socioeconomic position modifies the effects of birth weight and cognitive function on adult mortality.

\section{METHODS \\ Study population}

According to official statistics, 12270 boys were born within the metropolitan area of Copenhagen during 1953. These boys formed the study population of the Danish longitudinal study called Project Metropolit: a sociological study that was carried out at the Department of Sociology, University of Copenhagen, from 1965 to 1975, with the aim of examining social mobility. ${ }^{14}$

In April 1968, the Danish Civil Registration System (CRS) was established, and a unique 10 digit personal identification number (which includes the day, month and year of birth of the person) was allocated to all persons alive and living in Denmark at that time. This register keeps updated information on vital status and emigration for each person.

A total of 11532 of the males born in the Copenhagen region in 1953 were registered in the CRS (that is, alive and living in Denmark in 1968). Those not identified in the CRS in 1968 were either dead $(\mathrm{n} \sim 500)$ or had emigrated from Denmark. ${ }^{14}$ We excluded 156 subjects from the dataset 
Table 1 Characteristics of 7319 male singletons in the cohort. Percentage with birth weight below $2500 \mathrm{~g}$, percentage in the lowest quartile of cognitive tests, and crude risk of all cause mortality between age $15-49$ years $195 \%$ confidence intervals) according to characteristics

\begin{tabular}{|c|c|c|c|c|c|}
\hline & $\mathrm{N}(\%)$ & $\begin{array}{l}\text { Birth weight below } \\
2500 \mathrm{~g}(\%)\end{array}$ & $\begin{array}{l}\text { Lowest IQ test } \\
\text { quartile (\%) }\end{array}$ & $\begin{array}{l}\text { Lowest creativity } \\
\text { test quartile (\%) }\end{array}$ & Crude hazard ratio \\
\hline \multicolumn{6}{|c|}{$\begin{array}{l}\text { Socioeconomic position in early life } \\
\text { Father's social class at time of birth }\end{array}$} \\
\hline High/middle class & $3331(45.5)$ & 3.0 & 17.9 & 22.9 & 1.00 (ref) \\
\hline Working class & $3543(48.4)$ & $4.1^{*}$ & $33.1^{*}$ & $34.5^{*}$ & $1.41(1.17$ to 1.69$)$ \\
\hline Unknown & $445(6.0)$ & $5.8^{*}$ & $36.9^{*}$ & $32.9^{*}$ & $2.00(1.46$ to 2.74$)$ \\
\hline \multicolumn{6}{|c|}{ Mother's marital status at time of birth } \\
\hline Married & $6821(93.3)$ & 3.5 & 25.4 & 28.6 & 1.00 (ref) \\
\hline Unmarried & $481(6.7)$ & $6.5^{*}$ & $39.3^{*}$ & $33.8^{*}$ & $1.56(1.17$ to 2.07$)$ \\
\hline Unknown & $7(0.0)$ & & & & - \\
\hline \multicolumn{6}{|l|}{ Birth weight } \\
\hline$-2499 g$ & $269(3.7)$ & & $33.8^{*}$ & $40.1^{*}$ & $1.69(1.14$ to 2.51$)$ \\
\hline $2500-3499 \mathrm{~g}$ & $3644(49.8)$ & & 26.6 & 28.4 & 1.23 (1.03 to 1.47$)$ \\
\hline $3500 \mathrm{~g}+$ & $3402(46.5)$ & & 25.4 & 28.9 & 1.00 (ref) \\
\hline Unknown & $4(0.0)$ & & & & - \\
\hline \multicolumn{6}{|c|}{ Cognitive function at age 12 years } \\
\hline \multicolumn{6}{|c|}{ Härnquist IQ test } \\
\hline Lowest quartile & $1924(26.3)$ & $4.7^{*}$ & & $54.7^{\star}$ & $1.71(1.34$ to 2.19$)$ \\
\hline Second quartile & $1840(25.1)$ & $4.6^{*}$ & & $32.4^{*}$ & $1.30(1.00$ to 1.69$)$ \\
\hline Third quartile & $1784(24.4)$ & $3.3^{*}$ & & $17.8^{*}$ & 1.12 (0.83 to 1.47$)$ \\
\hline Highest quartile & $1771(24.2)$ & 1.9 & & 9.0 & 1.00 (ref) \\
\hline \multicolumn{6}{|l|}{ Creativity test } \\
\hline Lowest quartile & $2126(29.1)$ & $5.1^{*}$ & $49.5^{*}$ & & $1.48(1.16$ to 1.82$)$ \\
\hline Second quartile & $1755(24.0)$ & $3.8^{*}$ & $27.8^{*}$ & & $1.27(0.98$ to 1.65$)$ \\
\hline Third quartile & $1618(22.1)$ & $3.2^{*}$ & $17.6^{*}$ & & $1.23(0.95$ to 1.61$)$ \\
\hline Highest quartile & $1820(24.9)$ & 2.3 & 5.5 & & 1.00 (ref) \\
\hline
\end{tabular}

because they had requested that the CRS not disclose any information for research purposes. The remaining 11376 persons constituted the Metropolit2000 Cohort which is the study population in this study.

\section{Data sources and variables}

In Denmark, data from all births are thoroughly entered into registers and birth certificates. When Project Metropolit was established in 1965, all available information from such certificates and registers was collected manually for the entire original study population. ${ }^{14}$ Information on date and place of birth, singleton or multiple birth, birth weight and length, father's occupation, and mother's age and marital status at time of delivery was included.

In 1965, the members of this cohort were given a questionnaire by their teachers in the classroom. The survey included an IQ test developed by Kell Härnquist, translated from Swedish, ${ }^{15}$ and a test of creativity (the Remote Associates test), developed by Sarnoff A Mednick. ${ }^{16}$ A number of boys, corresponding to 7877 (68.3\%) of the Metropolit2000 cohort, participated in the school survey. The main reasons for nonparticipation in the survey were reported as general nonparticipation in school or class, individual absence from school on the day of data collection, and severe handicap or enrolment in special schools. ${ }^{14}$ Non-participants had the same mean birth weight than participants (3390 g), were more often born to single mothers ( $11.1 \%$ compared with $6.5 \%$ ), and had a higher proportion of fathers with unknown occupation ( $15.1 \%$ compared with $8.7 \%$ ).

In January 2002, the Metropolit2000 cohort was followed up for information on vital status in the CRS. If the person was not alive, or was living outside Denmark, information on date of death/emigration/disappearance was gathered. We identified causes of death for the period of April 1968 to December 1998 by record linkage to the Cause of Death Registry at the National Institute of Public Health. A total of 152 boys (1.9\%) born as twins or triplets and 232 boys (3.0\%) with missing birth data were excluded, leaving 7493 cohort members for the analyses.
From birth records, we used information on birth weight and the two available indicators of socioeconomic position in early life: father's social class and mother's marital status at the time of delivery. Father's social class was classified according to the father's position in the occupational structure of the society. Subjects were assigned, on the basis of father's occupation, into 23 strata: non-urban self employed (4 strata); urban self employed (6 strata); white collar workers ( 5 strata); blue collar workers ( 5 strata); pensioners; students; and unknown. The preliminary data analyses showed that the estimates for self employed and white collar workers were very close, and they were consequently combined, leaving three categories: high/middle class, which included self employed and salaried employed; working class, which included skilled and unskilled workers; unknown, which also included the small groups of pensioners $(n=1)$; and students $(n=44)$. When the analyses were stratified according to social class, we combined working class and unknown in one category, termed "low social class." Marital status of mothers was treated in two categories: married, and unmarried (that is, single, divorced, widowed). Birth weight was recorded in 100 gram groups and was analysed both as a continuous variable and in each of the five categories: <2500; 2500-2999; 3000-3499; 3500-3999; and $\geqslant 4000 \mathrm{~g}$. The initial data analyses showed that the estimates were nearly the same for the second and third and for the two largest categories, and, consequently, they were combined.

From the school questionnaire, we used the information on IQ and creative potential. The IQ test consisted of spatial, arithmetic and verbal sub-tests. In the spatial test, students were asked to choose one out of four alternative three dimensional figures, corresponding to a flat, two dimensional template. In the arithmetic test, students were to determine the logical sequences for a series of six numbers. In the verbal test, students were to identify, out of four alternatives, the antonym of a given word. Each sub-test included 40 problems, with a correct answer counting for one point, resulting in a range of 0-40 points. The overall test ranged from 0 to 120 points, with 
Table 2 Hazard ratios for all cause mortality between ages 15 and 49 (95\% confidence intervals) in relation to paternal social position, adjusted for birth weight and cognitive function for 7308 male singletons born in 1953

\begin{tabular}{|c|c|c|c|c|c|}
\hline & \multicolumn{5}{|c|}{ Mortality risk ages 15 to 49} \\
\hline & Model 1 & Model 2 & Model 3 & Model 4 & Model 5 \\
\hline \multicolumn{6}{|l|}{ Father's social class } \\
\hline High/middle class & 1.00 (ref) & 1 (ref) & 1.00 (ref) & 1.00 & 1.00 (ref) \\
\hline Working class & 1.401 .17 to 1.63$)$ & 1.31 (1.07 to 1.57$)$ & $1.32(1.12$ to 1.62$)$ & 1.30 (1.08 to 1.57$)$ & 1.30 (1.08 to 1.57$)$ \\
\hline Unknown & $1.94(1.42$ to 2.66$)$ & 1.85 (1.32 to 2.50$)$ & $1.98(1.42$ to 2.74$)$ & $1.83(1.32$ to 2.51$)$ & 1.81 (1.32 to 2.49$)$ \\
\hline \multicolumn{6}{|l|}{ Birth weight } \\
\hline$-2400 \mathrm{~g}$ & 1.60 (1.08 to 2.38$)$ & & & & 1.54 (1.04 to 2.29 ) \\
\hline $2500-3400 \mathrm{~g}$ & $1.22(1.02$ to 1.45$)$ & & & & 1.21 (1.01 to 1.44$)$ \\
\hline $3500 \mathrm{~g}+$ & 1.00 (ref) & & & & 1.00 (ref) \\
\hline \multicolumn{6}{|l|}{ Härnquist IQ test } \\
\hline Lowest quartile & & 1.55 (1.21 to 2.00$)$ & & 1.45 (1.10 to 1.93$)$ & 1.53 (1.19 to 1.97$)$ \\
\hline Second quartile & & $1.22(0.94$ to 1.59$)$ & & $1.16(0.88$ to 1.54$)$ & $1.20(0.92$ to 1.51$)$ \\
\hline Third quartile & & $1.08(0.82$ to 1.43$)$ & & $1.06(0.80$ to 1.39$)$ & 1.07 (0.81 to 1.41$)$ \\
\hline Higest quartile & & 1.00 (ref) & & 1.00 (ref) & 1.00 (ref) \\
\hline \multicolumn{6}{|l|}{ Creativity test } \\
\hline Lowest quartile & & & $1.40(1.09$ to 1.78$)$ & 1.17 (0.89 to 1.54$)$ & \\
\hline Second quartile & & & 1.22 (0.94 to 1.59$)$ & $1.10(0.83$ to 1.44$)$ & \\
\hline Third quartile & & & $1.21 \quad(0.93$ to 1.58$)$ & 1.14 (0.86 to 1.49$)$ & \\
\hline Higest quartile & & & 1.00 (ref) & 1.00 (ref) & \\
\hline
\end{tabular}

Besides paternal social class, model 1 includes birth weight; model 2 includes Härnquist IQ test; model 3 includes the Mednick Creativity test; model 4 includes both cognitive tests; and the final model 5 includes paternal social class, birth weight, and Härnquist IQ test.

the highest value reflecting the best score. In the creativity test, students were to come up with a word that was associated somehow with three other rather different words. This test included 25 different word series, and each correct answer counted for 1 point, giving a scoring range of 0 to 25 points. Cause of death was based on official death certificates coded using the 7th Revision of the International Classification of Diseases for the years 1968-1969, the 8th Revision for 1970-1993, and the 10th Revision for 1994-1998. Cause of death was classified into the following selected end points: CVD (ICD7-codes 330-468; ICD8-codes 390-458; ICD10-codes I00-I52,I60-I99; ICD10-code K70); injuries and suicide (ICD7codes 800-999; ICD8-codes 800-999; ICD10-codes V01-Y99); and other causes (all other codes).

\section{Statistical methods}

Associations between covariates were analysed using logistic and linear regression models. Associations between socioeconomic position in early life and mortality were analysed using Cox's proportional hazards regression models, with age as the underlying time scale, and age in 1968 as time of entry. Men who emigrated or changed identity were censored at the date of this event. The proportional hazards assumption was evaluated for all variables by comparing estimated $\ln (-\ln )$ survivor curves over the different categories of the variables being investigated, compared with $\ln$ (analysis time)—the so called "log-log" plots-and by tests based on the generalisation of Grambsch and Therneau. ${ }^{17}$ Statistical interaction between father's social class and other covariates was evaluated using a likelihood ratio test. Statistical analyses were performed using STATA version 7

\section{RESULTS}

During follow up, 541 men had died, and 275 were censored due to emigration $(n=264)$ and disappearance or change of identity $(\mathrm{n}=11)$. The 300 censored subjects did not differ from the remaining cohort with respect to mean birth weight $(3400$ g) or percentage unmarried mothers, but they had a higher mean IQ (72.2 points versus 67.6 points) and their fathers were more often high/middle class (56.2\% versus $45.7 \%)$. A total of 174 men had missing information on one or both cognitive tests and were excluded from the analyses presented here.
The distribution of socioeconomic position in early life, birth weight, and results of the cognitive function tests at age 12 years for the cohort, is shown in table 1 . The unadjusted relative death intensity ratios, according to these characteristics, are also shown. We found a higher risk of death from age 15-49 years in sons of unmarried mothers, and sons of fathers in the working class or of unknown social class. Sons of unmarried mothers and sons of fathers in the two lower social classes also had a higher prevalence of low birth weight, compared with those with married mothers, and of low cognitive performance, compared with those with fathers from high/ middle class. Birth weight and the two cognitive tests were inversely associated with mortality later in life, and the proportion of a low cognitive test score decreased with an increase in birth weight category.

The effect of mother's single status on mortality attenuated considerably in all models when father's social class was entered, and, therefore, marital status was not included in the multivariable analyses. The association between father's social class and mortality was slightly reduced after controlling for birth weight, while the inclusion of IQ in the model caused a larger reduction of the social class estimate (table 2, model 1 and 2). The IQ and creativity tests were correlated ( $r=0.53)$; and when both variables were present in the model, the effect of the creativity test became insignificant (model 4). This was also seen in all other models, and, consequently, we excluded the creativity test from the final models. The inclusion of birth weight in the model with IQ did not affect the estimates for father's social class or IQ, while the effect of birth weight was attenuated. However, social class, birth weight, and IQ remained significantly associated with mortality in the final model (table 2, model 5).

The hazard ratio for birth weight below $2500 \mathrm{~g}$ seemed to be higher for the low social class (HR 1.69 ( 1.07 to 2.64)) than for the high social class (HR 1.07 (0.46 to 2.45)). The second estimate, however, was only based on 15 deaths, and the risk estimates for the intermediate birth weight category showed the opposite tendency. Thus, the test for statistical interaction between father's social class and birth weight was not significant $(p=0.15)$. Visual inspection of mortality rates for each category of birth weight and IQ in the different social strata did not indicate any additive modifications of effects.

Although log-log plots and tests of zero slope gave no indication of violation of the proportional hazard assumption, the relations seemed to differ slightly, when the analyses were 


\begin{tabular}{|c|c|c|}
\hline & \multicolumn{2}{|l|}{ Mortality risk in age groups } \\
\hline & Age $15-34$ years $(n=212)$ & Age $35-49$ years $(n=310)$ \\
\hline \multicolumn{3}{|c|}{ Father's social class at birth } \\
\hline High/middle class & 1.00 (ref) & 1.00 (ref) \\
\hline Working class & $1.32(0.97$ to 1.82$)$ & $1.30(1.02$ to 1.65$)$ \\
\hline Unknown & 1.96 (1.19 to 3.23$)$ & 1.72 (1.14 to 2.50$)$ \\
\hline \multicolumn{3}{|l|}{ Birth weight } \\
\hline$-2400 \mathrm{~g}$ & 1.10 (0.53 to 2.27$)$ & 1.87 (1.17 to 3.06$)$ \\
\hline $2500-3400 \mathrm{~g}$ & 1.09 (0.84 to 1.78$)$ & $1.27(1.01$ to 1.60$)$ \\
\hline $3500 \mathrm{~g}+$ & 1.00 (ref) & 1.00 (ref) \\
\hline \multicolumn{3}{|c|}{ Härnquist IQ test at age 12 years } \\
\hline Lowest quartile & 1.29 (0.86 to 1.92$)$ & 1.71 (1.23 to 2.37 ) \\
\hline Second quartile & 1.26 (0.84 to 1.88$)$ & $1.17(0.81$ to 1.65$)$ \\
\hline Third quartile & $1.02(0.67$ to 1.55$)$ & $1.11 \quad(0.77$ to 1.59$)$ \\
\hline Higest quartile & 1.00 (ref) & 1.00 (ref) \\
\hline
\end{tabular}

subdivided into early (age 15-34 years) and later (age 35-49 years) deaths (table 3 ). Father's social class was associated with mortality before and after age 35 years, while the inverse relations with birth weight and IQ remained persuasive for the later deaths. The adjusted associations between covariates and mortality from specific causes are given in table 4. Father's social class was significantly associated with deaths from CVD, violent, and other causes, before and after adjustment. When birth weight or IQ were controlled for, however, the effects were attenuated.

As a sensitivity analysis, all the reported analyses were repeated for all 7493 men, with cognitive test scores, in tertiles and including an additional category for those with missing data. This approach gave essentially the same results as those based on the subjects with complete information on all variables reported above.

\section{DISCUSSION}

In this cohort of Danish men born in 1953, we found a clear relation between adverse socioeconomic position in early life and increased mortality in young adulthood. Low birth weight and low childhood IQ were both associated with social disadvantage and increased adult mortality. Adjustment for birth weight and IQ somewhat decreased the hazard ratios for the indicator of childhood socioeconomic position (father's social class at time of birth), but the estimates for all three variables remained significant. Analyses of cause specific mortality revealed consistent, positive associations with father's social class.
One of the strengths of our study is follow up for mortality, which covered all cohort members. Losses to follow up, therefore, did not seem to result in a serious bias. Non-participants, however, included more boys from lower social classes, and, as special schools were not included in the school survey, it is most likely that this group also represents more boys with impaired mental skills. Thus, our conclusions might not apply to these disadvantaged groups. It should also be noted, in this context, that women were not present in the dataset. The information on social circumstances in early life was collected from birth registers of high quality, rather than relying on recall from the offspring in childhood or middle age. This might minimise subjective and biased classification of exposure status. Furthermore, cognitive function was assessed using two different measures in late childhood, at an age when test scores are assumed to be stable. ${ }^{18}$ On the other hand, we must admit that it could also be a study limitation to rely on data collected in another era; the current usefulness of measures of IQ and socioeconomic position in 1953 may fairly be questioned. In addition, we only had information on a few of the many other factors, such as adult socioeconomic position and behaviour, which might also confound and/or mediate the relation between socioeconomic position in early life and later mortality. However, looking at health in the long term by use of existing cohorts, while increasing the understanding of early life origins of adult chronic disease, will always have this problem. A few other study limitations should be considered. We showed that creative potential had no independent effect besides what was obtained by the IQ test, which measured three different cognitive skills. A possible explanation is that

Table 4 Hazard ratios for death between ages 15 and $45^{*}$ (95\% confidence intervals) from cardiovascular diseases, accidents/suicide, and other causes, in relation to father's social class, adjusted for birth weight and childhood IQ, for 7308 male singletons born in 1953

\begin{tabular}{|c|c|c|c|}
\hline & $\begin{array}{l}\text { Cardiovascular diseases } \\
(n=70)\end{array}$ & Injuries and suicides $(n=162)$ & $\begin{array}{l}\text { Death from other causes } \\
(n=215)\end{array}$ \\
\hline \multicolumn{4}{|l|}{ Father's social class at birth } \\
\hline High/middle class & 1.00 (ref) & 1.00 (ref) & 1.00 (ref) \\
\hline Working class & $1.54(0.91$ to 2.64$)$ & $1.09(0.78$ to 1.53$)$ & 1.34 (0.93 to 1.83 ) \\
\hline Unknown & 3.64 (1.75 to 7.53$)$ & $1.94(1.14$ to 3.28$)$ & 1.82 (0.90 to 2.92$)$ \\
\hline \multicolumn{4}{|l|}{ Birth weight } \\
\hline$-2499 \mathrm{~g}$ & $1.75(0.68$ to 4.52$)$ & $1.87(0.95$ to 3.66$)$ & 2.06 (1.19 to 3.58$)$ \\
\hline $2500-3499 \mathrm{~g}$ & $0.96(0.60$ to 1.56$)$ & 1.33 (0.95 to 1.83$)$ & 1.24 (0.94 to 3.65$)$ \\
\hline $3500 \mathrm{~g}+$ & 1.00 (ref) & 1.00 (ref) & 1.00 (ref) \\
\hline \multicolumn{4}{|l|}{ Härnquist IQ test score at age 12} \\
\hline per quartile decrease & 1.10 (0.88 to 1.35$)$ & 1.16 (1.01 to 1.35$)$ & 1.17 (1.04 to 1.33 ) \\
\hline
\end{tabular}


the tests were correlated, and, given the sample size of our study, the independent effects of both variables could not be supported. It should also be noted questions have been raised as to what IQ tests actually measure. ${ }^{19}$ Furthermore, the small number of cause specific deaths reduce statistical power and allow no firm conclusions to be drawn from these data.

These analyses only included a single measure of socioeconomic position in early life. We had information on participants' occupation at age 20 years, but these data were incomplete and consequently not used in this study. On the other hand, the association between social position in early life and adult mortality has been shown in a variety of studies, even after taking account of socioeconomic circumstances in adulthood..$^{1-320}$ A recent study from a cohort born in 1946, in the UK, demonstrated that mortality between ages 26 and 54 was strongly influenced by social circumstances in childhood as well as in early adulthood. A trivial effect of entering adult social indicators into models of childhood social position upon mortality indicated that these influences operate through different pathways, and that childhood social position is not simply a proxy for adult living conditions. ${ }^{3}$ We have no reasons to believe that the findings from the 1946 cohort should not apply for the Danish cohort, which in many respects is comparable with the UK cohort.

In this study, inclusion of birth weight and childhood IQ in the model reduced the risk estimates for father's social class, indicating that these two variables mediate some of the effect. We also found the expected positive association between birth weight and IQ, and, in addition, our study showed that the effect of birth weight on mortality was attenuated when IQ was entered into the model. The latter finding suggests that cognitive function might be one of the pathways through which birth weight exerts its effect on mortality in adulthood. Thus, our study seems to support the postulated model (fig l). We compared a Cox model that contained the intermediate variables to one that did not. This approach could be used to assess how much of the association between socioeconomic position and mortality could be accounted for by birth weight and IQ. We must admit, however, that such a measure depends on the chosen cut off points and reference category used, and there is no way to judge its precision..$^{21}$ It is also advisable to use more complex models, such as structural equation models, to quantify the direct and indirect causal pathways postulated in a given lifecourse model. ${ }^{42}$ In the follow up study of children born in Aberdeen, Scotland, ${ }^{8}$ structural equation modelling was used to test direct effects of IQ at age 11, and of father's occupation at age at death. The most fitting model interpreted IQ as a mediating factor between father's occupation and age at death, while the models that assumed a direct effect of the social factor on age at death were not acceptable. It should be noted, however, that the Scottish analysis was restricted to those who died during follow up. The reason may be that the empirical model that treats social position in early life as a direct and mediating variable (through IQ) cannot easily be implemented in the Cox model.

Similar to the findings from a Finnish cohort study of 4630 men, ${ }^{7}$ our data suggested that the relation between birth weight and adult health is particularly strong in the lower social classes. This result indicates that social influences that alter growth also may change the risk of disease in adult life, and this supports a critical period model with modification of later effects.

CVD mortality was inversely related to father's social class. The same was true of violent deaths, although to a smaller extent. Clear effects of childhood socioeconomic position have also been seen for CVD in a number of previous studies. ${ }^{320}$ This seems to support the postulated mechanisms related to accumulation of socially patterned risk factors for CVD. A number of non-exclusive explanations, however, exist for the association of socioeconomic position in early life with adult mortality. Birth weight and IQ may reflect genetic factors for

\section{Key points}

- Men with adverse socioeconomic position in early life have higher rates of mortality in young adulthood, even after control for birth weight and childhood cognitive function.

- Low birth weight and low IQ are both related to adverse socioeconomic position in early life, and to increased mortality in young adulthood. This suggests a cumulative influence of socially patterned exposures across childhood, on mortality.

- The relation between birth weight and adult health seems to be particularly strong in those with adverse socieconomic position in early life.

\section{Policy implications}

- The mechanisms mediating the association between childhood socioeconomic position and health later in life have scarcely been investigated, but this knowledge is important for the prevention of such inequities. Birth weight and childhood cognitive function seem to be modifiable links.

- This points up the importance of prevention strategies to improve the health of socioeconomically disadvantaged families, even before they have children.

early mortality, but could also be considered as proxy measures of a number of different environmental and behavioural factors that tend to cluster in families-primarily for social reasons-and this would influence the health of the members of these families. ${ }^{5}$ The relation between birth weight and childhood IQ could also support the hypothesis of a biological pathway, which suggests that malnutrition in early life affects the development of the brain and later cognitive function. IQ has also been related to final qualifications and adult behaviour, such as smoking, thus supporting the notion that this psychometric characteristic may influence health. ${ }^{8}$ The potential health effects of socioenvironmental exposures over a lifetime have been described in different lifecourse models. ${ }^{45}$ The sensitive period model states that the environment in early life influences later susceptibility to disease, while the cumulative effect model suggests an added influence of the number and/or duration of health damaging exposures, across the lifecourse, on disease risk. Low birth weight and low IQ were most prevalent in sons of fathers in the lower social classes and each exposure exerted an independent effect on mortality. The risk increased with the number of unhealthy exposures, and, consequently, our study seems to demonstrate a cumulative influence of socially patterned exposures, across the lifecourse, on mortality risk. ${ }^{45}$ Adjustment for the social class difference in birth weight and IQ, however, only explained a part of the observed social variation in mortality. This finding suggests that a sensitive period model also plays a part, although it should be noted that we only addressed a subset of the health related factors linked to socioeconomic position in early life.

In conclusion, this study provides support for the existence of a relation between socioeconomic position in early life and adult mortality in men, which cannot be fully accounted for by birth weight or childhood cognitive function.

\section{ACKNOWLEDGEMENTS}

We thank all those who initiated and/or continued the study from 1965 to 1983-K Svalastoga, E Høgh, P Wolf, T Rishøj, G Strande-Sørensen, E Manniche, B Holten, I A Weibull, and A Ortmann-for their thorough work on the project. Thanks to Knud Juel for providing data on causes of death. 


\section{Authors' affiliations}

$M$ Osler, A-M N Andersen, P Due, R Lund, M T Damsgaard,

B E Holstein, Department of Social Medicine, Institute of Public Health, University of Copenhagen, Copenhagen, Denmark

Funding: Danish Heart Association.

Conflicts of interest: none declared.

\section{REFERENCES}

1 Davey Smith G, Gunnel D, Ben-Shlomo Y. Life-course approaches to socio-economic differentials in cause-specific adult mortality. In: Len D, Walt $G$, eds. Poverty, inequality and health. An international perspective. Oxford: Oxford University Press, 2000:88-124.

2 Kuh D, Hardy R, Langenberg C, et al. Mortality in adults aged 26-54 years related to socioeconomic conditions in childhood and adulthood: postwar birth cohort study. BM 2002;325:1076-80.

3 Frankel S, Davey Smith G, Gunnell D. Childhood socioecnomic position and adult cardiovascular mortality: the Boyd Orr Cohort. Am J Epidemio 1999:150:1081-4.

4 Ben-Shlomo Y, Kuh D. A life course approach to chronic disease epidemiology: conceptual models, emperical challenges and interdiciplinary perspectives. Int J Epidemiol 2002;31:285-93

5 Hertzman C. The biological embedding of early experience and its effect on health in adulthood. Ann NY Acad Sci 1995;896:85-95.

6 Bartley M, Power C, Blane D, et al. Birth weight and later socioeconomic disadvantage: evidence from the 1958 British cohort study. BM 1994;309:1475-9

7 Barker DJP, Forsen T, Uutela A, et al. Size at birth and resilience to effects of poor living conditions in adult life: longitudinal study. BM 2001;323:1273-5.

8 Whalley LJ, Deary IJ. Longitudinal cohort study of childhood IQ and survival up to age 76 . BM $2001 ; 322: 1-5$
9 Barker DIP. Mothers babies and disease later in life. London: BMU Publishing Group, 1994.

10 Leon DA, Lithell HO, Vågerö D, et al. Reduced fetal growth rate and increased risk of death from ischemic heart disease: cohort study of 15,000 Swedish men and women 1915-29. BM 1998;317:241-5.

11 Richards $M$, Hardy R, Kuh D, et al. Birth weight and cognitive function in the British 1946 birth cohort: longitudinal population study. BM 2001;322:199-203.

12 Sørensen HT, Sabroe S, Olsen J, et al. Birth weight and cognitive function in young adult life: historical cohort study. BM 1997;315:401-3.

13 Jefferis BJMH, Power C, Hertzman C. Birth weight, childhood socioeconomic environment, and cognitive development in the 1958 British birth cohort study. BM 2002;325:305-8.

14 Høgh E, Wolf P. Project Metropolitan: a longitudinal study of 12,270 boys from the Metropolitan Area of Copenhagen, Denmark, 1953-1977. In: Mednick SA, Baert AE, eds. Prospective longitudinal research. London: Oxford University Press, 1981.

15 Svensson A. Sociale och regionala faktorers samband med över- och underpresentation i skolearbetet. Pedagogiska institutionen. Göteborgs: Göteborgs Universitet, 1964.

16 Mednick SA.The association basis of the creative process. Psychol Rev 1962;69:202-32.

17 Grambsch PM, Therneau TM. Proportional hazard tests and diagnostics based on weighted residuals. Biometrika 1994;81:515-26.

18 Schuerger JM, Witt AC. The temporal stability of individually tested intelligence. J Clin Psychol 1989:45:294-302.

19 Sternberg RJ. The holy grail of intelligence. Science 2000;289:399_ 401.

20 Davey Smith G, Hart C, Blane D, et al. Lifetime socioeconomic position and mortality: prosepctive observational study. BM 1997;314:547-52.

21 Ditlevsen S, Christensen U, Lynch J, et al. The mediation proportion: a structural equation approach with an application to a common problem in social epidemiology. Research report 02/11. Copenhagen: University of Copenhagen, Department of Biostatistics, 2002 


\section{PostScript}

\section{LETTER}

If you have a burning desire to respond to a paper published in the JECH, why not make use of our "rapid response" option?

Log on to our website (www.jech.com), find the paper that interests you, and send your response via email by clicking on the "eletters" option in the box at the top right hand corner.

Providing it isn't libellous or obscene, it will be posted within seven days. You can retrieve it by clicking on "read eletters" on our homepage.

The editors will decide as before whether to also publish it in a future paper issue.

\section{Divorce and suicide risk}

There is accumulating evidence that divorced and separated people have much higher suicide rates than their married counterparts. In a previous paper published in this journal, it was observed that divorced and separated men were nearly 2.4 times more likely to kill themselves than their married counterparts.
That study, however, failed to directly compare divorced men and women. While it informed us that divorced people are at higher risk of suicide than the married, it said nothing about the suicide risk of divorced men relative to divorced women. The purpose of this communication is to assess the magnitude of the differentials in suicide risk between the two groups, and explore possible reasons that might explain the disparities.

Data were obtained from the US National Longitudinal Mortality Study (NLMS), 1979$1989^{2}$ and covariates used were taken from Kposowa. ${ }^{1}$ The response variable was the risk of suicide, and analysis was restricted to divorced and separated non-Hispanic white men and women. Proportional hazards regression models were fitted to the data, and relevant results are in table 1.

Model 1 presents the age adjusted effects of sex on the risk of suicide. Divorced men were over eight times more likely to commit suicide than divorced women ( $R R=8.36$, $95 \% \mathrm{CI}=4.24$ tol6.38). After taking into account other factors that have been reported to contribute to suicide, divorced men still experienced much increased risks of suicide than divorced women. They were nearly 9.7 times more likely to kill themselves than

Table 1 Hazards regression estimates of the impact of divorce on the risk of white suicide

\begin{tabular}{|c|c|c|c|c|c|c|}
\hline \multirow[b]{2}{*}{ Covariate } & \multirow[b]{2}{*}{ Suicides } & \multirow{2}{*}{$\begin{array}{l}\text { Population } \\
\text { at risk }\end{array}$} & \multicolumn{2}{|l|}{ Model 1} & \multicolumn{2}{|c|}{ Model 2} \\
\hline & & & RR & $95 \% \mathrm{Cl}$ & RR & $95 \% \mathrm{Cl}$ \\
\hline \multicolumn{7}{|l|}{ Sex } \\
\hline Women & 10 & 16687 & 1.00 & (Reference) & 1.00 & (Reference) \\
\hline Men & 53 & 10917 & $8.33^{* *}$ & $\begin{array}{l}4.24 \text { to } \\
16.38\end{array}$ & $9.68^{* *}$ & 4.87 to 19.22 \\
\hline \multicolumn{7}{|l|}{ Age (y) } \\
\hline $25-34$ & 20 & 8586 & 1.00 & (Reference) & 1.00 & (Reference) \\
\hline $35-44$ & 17 & 6417 & 1.37 & 0.71 to 2.62 & 1.45 & 0.76 to 2.78 \\
\hline $45-64$ & 21 & 8003 & 1.48 & 0.80 to 2.73 & 1.48 & 0.79 to 2.77 \\
\hline $65+$ & 5 & 2322 & 1.50 & 0.56 to 3.99 & 1.24 & 0.44 to 3.47 \\
\hline \multicolumn{7}{|l|}{ Education (y) } \\
\hline$<$ High school & 16 & 7182 & & & 1.00 & (Reference) \\
\hline High school & 26 & 11387 & & & 0.76 & 0.40 to 1.45 \\
\hline Some college & 17 & 7135 & & & 0.96 & 0.54 to 1.81 \\
\hline \multicolumn{7}{|l|}{$\begin{array}{l}\text { Household } \\
\text { income }\end{array}$} \\
\hline$\$ 25000+$ & 9 & 3615 & & & 1.00 & (Reference) \\
\hline Below $\$ 10000$ & 28 & 10654 & & & $2.31^{*}$ & 1.05 to 5.09 \\
\hline $\begin{array}{l}\$ 10000- \\
\$ 24999\end{array}$ & 23 & 11886 & & & 1.12 & 0.51 to 2.45 \\
\hline $\begin{array}{l}\text { Income } \\
\text { unknown }\end{array}$ & 3 & 1449 & & & 1.21 & 0.32 to 4.48 \\
\hline $\begin{array}{l}-2 \log L \\
\text { IRS }\end{array}$ & & & $\begin{array}{l}1226.08 \\
57.04^{* *}\end{array}$ & & & $\begin{array}{l}1218.85 \\
6427^{* *}\end{array}$ \\
\hline & & & 4 & & & 9 \\
\hline $\begin{array}{l}\text { Number of } \\
\text { suicides }\end{array}$ & & & 63 & & & 63 \\
\hline $\begin{array}{l}\text { Number of } \\
\text { cases }\end{array}$ & & & 27604 & & & 27604 \\
\hline
\end{tabular}

${ }^{*}$ Significant at $\mathrm{p}<0.05$. ${ }^{*}$ Significant at $\mathrm{p}<0.01$. LRS, likelihood ratio statistic; $\mathrm{df}$, degrees of freedom $\mathrm{RR}$, relative risk; $\mathrm{Cl}$, confidence intervals. comparable divorced women $(\mathrm{RR}=9.68,95 \%$ $\mathrm{CI}=4.87$ to 19.22). Put another way, for every divorced woman that committed suicide, over nine divorced men killed themselves.

These results dramatise the terrible consequences of being a divorced man in America, and lead to the question: why are divorced men killing themselves? Some analysts argue that the research community has ignored a plausible explanation for the excess suicide risks experienced by divorced men. As Perrault ${ }^{3}$ and Farrell $^{4}$ observe, while social, psychological, and even personal problems facing women are readily denounced, societal institutions tend to ignore or minimise male problems as evident in suicide statistics. For instance, in many jurisdictions in the US there seems to be an implicit assumption that the bond between a woman and her children is stronger than that between a man and his children. ${ }^{5}$ As a consequence, in a divorce settlement, custody of children is more likely to be given to the wife. In the end, the father loses not only his marriage, but his children. The result may be anger at the court system especially in situations wherein the husband feels betrayed because it was the wife that initiated the divorce, or because the courts virtually gave away everything that was previously owned by the ex-husband or the now defunct household to the former wife. Events could spiral into resentment (toward the spouse and "the system"), bitterness, anxiety, and depression, reduced self esteem, and a sense of "life not worth living". As depression and poor mental health are known markers of suicide risk, it may well be that one of the fundamental reasons for the observed association between divorce and suicide in men is the impact of post divorce (court sanctioned) "arrangements". Clearly this is an issue that needs further investigation.

A J Kposowa

Department of Sociology, University of California, 1214 Watkins Hall, 900 University Avenue, Riverside, CA 92521, USA; ajkposowa@att.net

\section{References}

1 Kposowa AJ. Marital status and suicide in the National Longitudinal Mortality Study. J Epidemio Community Health 2000:54:254-61.

2 National Heart, Lung, and Blood Institute. National Longitudinal Mortality Study 19791989 [Machine-readable public use data tape] Bethesda, MD: National Institutes of Health, 1995.

3 Perrault C. And if we speak about men? Sante Ment Que 1990;15:134-44.

4 Farrell W. The myth of male power. New York: Simon and Schuster, 1993.

5 Furstenberg FF, Sherwood KE, Sullivan ML. Caring and paying: what fathers and mothers say about child support. New York: Manpower Demonstration Research, 1992. 


\section{BOOK REVIEWS}

\section{Ethical dimensions of health policy}

Edited by M Danis, C Clancy, L R Churchill. (Pp 394; £37.50). Oxford University Press, 2002. ISBN 0-19-514070-2

The main aim of the book is to examine the connections between ethics and health policy. Experts from different disciplines and spheres have contributed. The book is structured in four parts. From an ethical deliberation on healthcare goals readers proceed through an intermediate chapter to political decision making. The final chapter deals with ethical controversies on the resource allocation, accountability, vulnerability, and ethics of the health services research.

The book focuses to a large extent on the US reality and provides an insight into the history of their healthcare reforms as well as the recent debate on a universal healthcare system based on social solidarity. European or other readers may learn from a very profound and sophisticated consideration of how ethical and political approaches may interfere. The pragmatic claim that the bioethical debate descends from academic heights and influences directly political decisions is illustrative. Readers face the debate on justice from a reverse side. Concepts that are taken for granted in Europe are being vindicated and legitimised (Rawls is repeatedly reflected). An outline of a future collective and organisational rather than personal accountability for health care is innovative (Cassel, McParland). The postmodern practice as delineated by Malone and Luft may be viewed as visionary although stimulating. New health services research agenda such as research of trust, privacy, internet practices has been suggested.

Several conclusions seem to be self evident, sometimes an effort to square the circle may be suspected. However, the focus on inherence of values in policy making, on negotiating culture and procedural aspects as crucial in setting and implementing healthcare goals makes the text instructive. A lesson of democracy in health care is the essence that readers breathe as the fresh air at each page. Even when not all authors share the same opinion the book is illuminated by an optimistic faith that connecting ethics and health policy is viable - a sustainable health policy necessitates a moral legitimacy and bioethics shall promote the social action.

E Køížová (Krizova)

\section{World report on violence and health}

E G Krug, L Dahlberg, J Mercy, A Zwi, R Lozano. (Pp 346 ; US\$27.00). Geneva: WHO Library Cataloguing-in-Publication Data, 2002. ISBN 92-4-154561-5

Violence was declared in Resolution WHA49.25 (1996) as a major and growing public health problem across the world. This is the first world report on violence and health aimed mainly to raise awareness about the issue of violence globally and to make the case that violence is preventable and that public health has a crucial part to play in tackling its causes and consequences.

The report has been structured in nine chapters, starting with a general one of violence as a global public health problem followed by specific information about different types of interpersonal violence (youth violence, child abuse, violence against intimate partners, abuse of elderly people, and sexual abuse), self directed violence (suicide), and collective violence, and completed by nine recommendations for research and actions at local, national, and international levels. The report also includes a statistical annex with estimated mortality caused by each kind of violence and a list of internet resources.

It provides further information about the magnitude and impact of each type of violence reported; identifies risk factors like social, cultural, and economical stressors and determines as precipitant factors the presence of alcohol, drugs or weapons; it also gives an account of the types of intervention and policy responses that have been already used and summarises what is known about their effectiveness.

The most important strength of this report is the efforts implied to summarise what is known about this problem around the world. It is a useful document for those who are involved in research or prevention on violence. However, the lack of information to complete a global approach about the risk and protective factors, interventions, and evaluation of the effectiveness of policy responses is recognised.

This weakness has tried to be solved by the recommendations for action. However, most of them are not new and not practical enough for those who are dedicated to this issue.

On the one hand, the recommendations about how to create, implement, and monitor a national action plan for violence prevention, to increase capacity for collecting data on violence, to support research on the causes, consequences, costs, and prevention of violence and to promote primary prevention responses have been already well documented. In the same way, other official documents have already shown evidence about the importance of training for health and education professional, the coordination between public and private sectors, and the strengthening of the community base.

On the other hand, the recommendations related to the importance of producing information about the cost of violence for health services and the prevention in primary health are much too narrow to speak about a true public health approach on violence.

Although it provides useful information about each type of violence in each country, a comprehensive account of the resources needed to cope with violence from a public health perspective is lacking through the book.

For these reasons, this first world report on violence and health can be considered as a valuable starting point about research responses to an old social and public health problem.

C V Cases

\section{Law in public health practice}

R A Goodman, M A Rothstein, R E Hoffman, W López, G W Matthews. Oxford University Press, 2003. (Pp 462; price not stated). ISBN 019-514871-1

The aim of this book, written jointly by a variety of law and public health practice specialist authors-who represent the ranks of the legal and public health practitioners in the United States of America-is to clarify the principles of law as they bear on the practice of public health.

The reader is invited to improve their understanding of the legal principles underlying public health practice; that is to say how law may be applied to improve the health of people. And after reading the book, this aspiration is reached, especially the discovery of the wide range of daily activities of public health where the legal dimension is present.

The first part is related with the conceptual foundations of the legal basis for public health practice and covers topics as constitutional and statutory basis, the applications of regulatory and criminal law-for example, infectious disease pathogens used as weapons of mass destruction-, and overarching areas like common ethical issues in public health such us the concerns about balancing benefits between communities and individuals or human rights. Also the book provides a framework that can guide practitioners' reflections in their decisions.

The last two parts examine the public health law infrastructure and make recommendations for needed improvements. With many selected examples the interrelation of law with the core functions of public health are thoroughly reviewed and documented: the interaction between public health practitioners and legal counsel, surveillance and outbreak investigations, research, confidentiality and privacy, managed care in public health, interventions in emergency response, and particular populations (children, homeless persons, disabilities, or undocumented immigrants). And also high priority and emerging areas in public health such as genomics, communicable diseases, public health emergencies, reproductive health, tobacco prevention, and environmental, injury, occupational issues.

It must be taken into account that the context of the book is the United States, but despite the fact of the peculiarities of its regulation, the basis and principles are applicable to any country beyond its own legislation and serves as a primary resource for promoting the development and implementation of an effective public health law infrastructure and increase the visibility and effectiveness of law as a tool for the promotion of the public's health. It is recommendable reading for public health practitioners wishing to improve their understanding about how the law affects the prevention of disease and injury.

E Ronda

R Rubio

\section{Case studies in forensic epidemiology}

S Loue. (Pp 203; price not stated). Kluwer Academic/Plenum Publishers, New York, 2002. ISBN 0-306-46792-5

Sane Loue's book Case studies in forensic epidemiology represents a significant turning point in our habitual conception of epiemiology as a statistical indicator of the extent to which the population is affected by some infectious - that is, toxicological-agent.

The reader is attracted by the title of the book itself because forensic epidemiology is 
much less elaborated in professional literature than some epidemiological research within different specialist fields of medical science. The author is very successful in presenting the application of forensic epidemiology, as well as its role in court trials, as a bridge between many criminal deviations of the society, and its responsibility for crimes committed. Her final goal is getting court and police officials to apply efficient changes to negative social actions.

In eight case studies within 12 chapters of the book the author describes the connection between court trials and important epidemiological analysis that can be found in the cases of many trials started by women smokers who had silicon breast implantations done, which consequently caused them serious health problems. In this connection the author describes the obstacles attorneys and judges are faced with while prosecuting powerful tobacco lobbies, pointing out the core of the problem, that is an evident hazardous effect of smoking to human health.

As a forensic expert I would point out case study five in chapter eight that deals with road accidents caused by drivers under the influence of alcohol. The fact that road accidents caused by drunk drivers represent the main cause of most such accidents, is corroborated by some alarming epidemiological data. In this connection, the author describes the activities of non-profit organisation Mothers Against Drunk Drivers, which achieves significant results in making the public aware of the problem. Moreover, they organise legal help to the families of the victims of such accidents, which makes the organisation recognisable and increasingly influential in trials against irresponsible drivers.

It was the author's goal, which she entirely managed to achieve, to explain the extremely important role of forensic epidemiology in court trials. To sum up, this extraordinary work represents a significant contribution to a succesful solving, within the framework of legal system, of difficult and painful court epidemiological problems of the society.

A Bosnar

\section{ActivEpi CD ROM}

D Kleinbaum. Springer, 2002. ISBN 0-38714257-6

ActivEpi is a multimedia presentation of the material commonly found in an introductory epidemiology course on CD ROM. In 15 lessons, basic concepts and measures of epidemiology are presented. ActivEpi is intended to be used in a variety of teaching formats, including distance learning, self paced learning on-campus courses, and short courses. The course uses a variety of tools including, among others, videos, narrated expositions, exercises, and datasets and quizzes for self evaluations.

With respect to the logical structure of the contents, this introduction is as stringent and clear as previous, more traditional teaching material by David Kleinbaum, including the classic 1982 textbook, ${ }^{1}$ which has, certainly, helped numerous epidemiologists and epi students around the world, including myself (who had the additional true privilege to experience David Kleinbaum as an outstanding "physical teacher"), to structure epidemiological reasoning. Whether or not the multimedia approach now offered by David Kleinbaum makes learning more attractive, easy, or effective than more traditional forms of learning in a classroom context or from an introductory textbook may to some degree be a matter of taste, generation, and personal preferences. Being aware that this carries the danger of being blamed old fashioned, I have to admit that I felt the multimedia features to be a little bit too abundant in this course, and sometimes even to be a source of distraction actually hindering concentrated learning rather than a real advantage. Perhaps younger generations of epidemiologists who have grown up with multimedia features from their cradle may appreciate this type of learning much more-I am afraid that I will continue to recommend my students a good personal teacher along with a good introductory textbook and/or course script. However, these resources may not be universally available. In such circumstances, this course may fill a real gap.

\section{H Brenner \\ Reference \\ 1 Kleinbaum DG, Kupper LL, Morgenstern H. Epidemiologic research. Principles and quantitative methods. New York: van Nostrand Reinhold, 1982.}

\section{Foundations for health improvement. Productive epidemiological public} health research 1919-1998

W W Holland. (Pp 236; price not stated). TSO, Norwich, 2002

For our young colleagues, the relevance of this book is justified by its reference lists alone, as these include most of the papers that provided the most important achievements of epidemiology and public health from 1919 onwards. The book is easy to consult and read, because for each calendar period the main topics are separately considered - that is, infectious diseases, occupational factors, nutrition, environment, etc. Thus, for instance, under the headings tobacco or air pollution, summary overviews are given on the earlier developments of research and control of these risk factors, which remain of central interest for their public health relevance today.

A second reason for appreciating this book is related to its attention to the major social and public health implications of our discipline. Over the past few years, we have seen (and participated to) endless debates on the potential impact of risk factors such as electromagnetic fields or hair dyes, whose public health relevance, if any, remains marginal. Furthermore, the interest of many of us has been often focused more to the publication of modest excess relative risks, than to the critical understanding and evaluation of their potential public health implications. It is thus a pleasure to read a book that provides an overview of the main achievements and contributions of our discipline to public health and society in its broader terms. The book also includes some interesting chapter on methodological developments (from questionnaires to statistical methods) and philosophy of medicine.

Most of us will also find of interest the chapter on trends in UK and US society and politics, which is unusually objective and far from strong partisan opinions, as well as those on the history of the development of public health departments in UK and US universities and other research institutions. In a period of conflicts of interest, the summary of main funding sources is also of important relevance.

A message drawn from the book is that, over the past few decades, US research in public health has improved more than its UK counterpart. Any comparison between public health institutions and achievements in the UK and the US, however, leaves most of who live and work outside those two countries - with a sense of admiration and envy.

\section{La Vecchia}

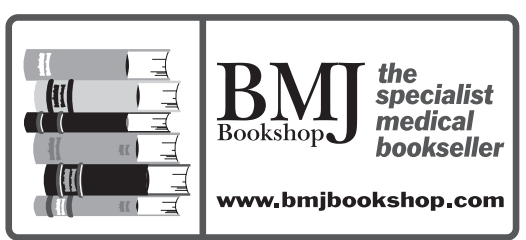

\section{NOTICE}

\section{Migrant health in Europe}

An international conference on differences in health and health care provision is to be held in Rotterdam, Netherlands, on 23-25 June 2004. Further details: Lilian Hoonhout, Department of Health Policy and Management, Erasmus MC, PO Box 1738 3000 DR Rotterdam, Netherlands (email: e.zoer@planet.nl; web site: http://www. migranthealth.net).

\section{CORRECTIONS}

An authors' error occurred in this paper by Dr Leung and others (2003;57:857-63). Professor Charles D Spielberger and Dr Paul Yung should have been acknowledged for granting permission to use the original and Chinese version of the State-Trait Anxiety Inventory.

An editorial error occurred in this article by Mr Geoff Der (2003;57:839). The picture credit was omitted and should have read "The illustration was reproduced with permission from the Whitworth Art Gallery, The University of Manchester. (c) Succession Picasso/DACS 2003."

An authors' error occurred in the paper by Dr Osler and others (2003:57:681-6). The 12th line in the first paragraph on page 683 should have read "100-152, 160-199; ICD10 (not ICD10-code K70). 